\section{D) Check for updates}

Cite this: Dalton Trans., 2017, 46, 7714

Received 17th April 2017

Accepted 10th May 2017

DOI: $10.1039 / c 7 d t 01384 a$

rsc.li/dalton

\title{
Two excellent phase-matchable infrared nonlinear optical materials based on 3D diamond-like frameworks: $\mathrm{RbGaSn}_{2} \mathrm{Se}_{6}$ and $\mathrm{RbInSn}_{2} \mathrm{Se}_{6} \dagger$
}

\author{
Hua Lin, ${ }^{a, b}$ Hong Chen, ${ }^{a, b}$ Yu-Jun Zheng, ${ }^{a, b, c}$ Ju-Song Yu, ${ }^{a, b, c}$ Xin-Tao Wu ${ }^{a}$ and \\ Li-Ming Wu (iD) *a,b
}

\begin{abstract}
Mid- and far-infrared (MFIR) nonlinear optical (NLO) crystals with excellent performances are critical to laser frequency-conversion technology. However, the current commercial MFIR NLO crystals, including $\mathrm{AgGaS}_{2}$ (AGS), AgGaSe 2 and $\mathrm{ZnGeP}_{2}$, suffer from certain intrinsic drawbacks and cannot achieve a good balance between large second-harmonic generation (SHG) efficiency and high laser-induced damage thresholds (LIDTs). Herein, we report two new phase-matchable MFIR NLO chalcogenides, specifically $\mathrm{RbXSn}_{2} \mathrm{Se}_{6}(X=\mathrm{Ga}, \mathrm{In})$, which were successfully synthesized by high-temperature solid-state reactions. The remarkable structural feature of these materials was their 3D diamond-like framework (DLF) stacked by $\mathrm{M}_{3} \mathrm{Se}_{9}(\mathrm{M}=\mathrm{X} / \mathrm{Sn})$ asymmetric building units of vertex-sharing $\mathrm{MSe}_{4}$ tetrahedra along the $c$ axis. Significantly, both of the materials showed the excellent NLO performances with the desired balance between their large SHG efficiencies (4.2 and $4.8 \times$ benchmark AGS) and large LIDTs (8.9 and $8.1 \times$ benchmark AGS), demonstrating that the title compounds meet the crucial conditions as promising MFIR NLO candidates. Furthermore, the crystal structures, synthesis, and theoretical analysis, as well as optical properties are presented herein
\end{abstract}

\section{Introduction}

In solid-state laser frequency-conversion techniques, secondorder nonlinear optical (NLO) crystals are key optoelectronic functional materials based on second-harmonic generation (SHG). Moreover, they also have very important applications in many fields, such as resource exploration, military communications, space anti-missiles and electro-optical countermeasures. ${ }^{1}$ In general, the state-of-the-art NLO materials can be divided into four classes based on their working wavelength ranges: deep-ultraviolet (DUV, below $200 \mathrm{~nm}$ ), ultraviolet-

\footnotetext{
${ }^{a}$ State Key Laboratory of Structural Chemistry, Fujian Institute of Research on the Structure of Matter, Chinese Academy of Sciences, Fuzhou, Fujian 350002, People's Republic of China

${ }^{b}$ Key Laboratory of Optoelectronic Materials Chemistry and Physics, Fujian Institute of Research on the Structure of Matter, Chinese Academy of Sciences, Fuzhou, Fujian 350002, People's Republic of China. E-mail: liming_wu@fjirsm.ac.cn; Tel: $+(011) 86-591-63173130$

${ }^{c}$ University of Chinese Academy of Sciences, Beijing 100039, People's Republic of China

$\dagger$ Electronic supplementary information (ESI) available: Additional crystallographic data, CIF files, TG-DTA, reflection and FT-IR spectra, calculation results, together with additional tables and figures. CCDC 1504918 and 1504919. For ESI and crystallographic data in CIF or other electronic format see DOI: 10.1039/ c7dt01384a
}

visible (UV-vis), near-infrared (IR) and mid-/far-infrared (MFIR) materials. To date, numerous well-known NLO crystals have been discovered that satisfy the practical requirements in the UV-vis and near-IR regions, such as $\mathrm{LiB}_{3} \mathrm{O}_{5}(\mathrm{LBO}){ }^{2}$ $\beta-\mathrm{BaB}_{2} \mathrm{O}_{4}(\mathrm{BBO}),{ }^{3} \mathrm{KH}_{2} \mathrm{PO}_{4}(\mathrm{KDP})^{4}$ and $\mathrm{KTiOPO}_{4}(\mathrm{KTP}) .{ }^{5}$ In contrast, materials working in the other two regions are still extremely rare. For example, $\mathrm{KBe}_{2} \mathrm{BO}_{3} \mathrm{~F}_{2}$ (KBBF) is the only practically usable material in the DUV region, but it has a serious layer growth habit and the constituent beryllium is highly toxic, which limits its wide application. ${ }^{6}$ In addition, only a few commercial NLO crystals, including $\mathrm{AgGaS}_{2}$ (AGS), $\mathrm{AgGaSe}_{2}$ and $\mathrm{ZnGeP}_{2}$, are available in the MFIR region, but unfortunately, they suffer from certain inherent drawbacks, such as a low laser-induced damage threshold (LIDT) and the two-photon absorption of $1 \mu \mathrm{m}$ laser, which seriously hinders their applications. ${ }^{7}$ Therefore, the search for new second-order MFIR NLO materials with excellent performances is extremely urgent. Usually, the desirable properties for an MFIR NLO material include the following conditions: (1) large SHG efficiency; (2) high LIDT; (3) moderate optical birefringence $(0.04<\Delta n<0.10)$; (4) broad MFIR transparency region; (5) good physico-chemical properties and thermal stability. ${ }^{8}$

Metal chalcogenides are the most promising materials for second-order NLO applications in the MFIR region due to their fascinating structural features, large SHG efficiency and wide 
optical transparency, and consequently they have attracted considerable research interest. A large number of non-centrosymmetric (NCS) metal chalcogenides with large SHG efficiencies have been explored and discovered during the last few decades. $^{9-58}$ Among these, examples that have both a large SHG efficiency $(>1 \times$ AGS) and a high LIDT are notably rare, but include $\mathrm{SnGa}_{4} \mathrm{Se}_{7},{ }^{31} \quad \mathrm{PbGa}_{2} \mathrm{GeSe}_{6},{ }^{37} \quad \mathrm{Na}_{4} \mathrm{MgGe}_{2} \mathrm{Se}_{6},{ }^{42}$ $\mathrm{Na}_{2} \mathrm{Hg}_{3} \mathrm{M}_{2} \mathrm{~S}_{8}(\mathrm{M}=\mathrm{Si}, \mathrm{Ge}, \mathrm{Sn}),{ }^{45}\left[\mathrm{AX}_{3}\right]\left[\mathrm{Ga}_{3} \mathrm{PS}_{8}\right](\mathrm{A}=\mathrm{K}, \mathrm{Rb} ; \mathrm{X}=$ $\mathrm{Cl}, \mathrm{Br}){ }^{48} \mathrm{Li}_{4} \mathrm{HgGe}_{2} \mathrm{~S}_{7}{ }^{54}$ and $\mathrm{NaGaIn}_{2} \mathrm{Se}_{6}{ }^{55}$ (a detailed comparison of the properties is displayed in Fig. 1). Moreover, research has shown that macroscopic polarization can be maximized only when the crystal structure belongs to one of the 10 polar point groups. ${ }^{59}$ As a consequence, the design and synthesis of novel NCS chalcogenides in the field of second-order MFIR NLO materials with a polar structure and good balance between a large SHG efficiency and high LIDT is a hot topic and remains a great challenge.

In an earlier study, we carried out exploratory synthesis on the quaternary alkali metals/transition metals/group 13 metals/chalcogenides $\left(\mathrm{A} / \mathrm{X}^{\mathrm{II}} / \mathrm{X}^{\mathrm{III}} / \mathrm{Q}\right)$ system and discovered a series of novel $\mathrm{AM}_{9} \mathrm{Q}_{12}\left(\mathrm{M}=\mathrm{X}^{\mathrm{II}} / \mathrm{X}^{\mathrm{III}}\right)$ polar compounds with a 3D diamond-like framework (DLF) ${ }^{60-64}$ Through a comprehensive analysis of the structure-property relationship, we found that 3D DLF structures can provide an adjustable platform for the rational and precise design and development of outstanding MFIR NLO materials. Recently, two new DLF compounds were discovered by our group, namely $\operatorname{CsM}_{3} \mathrm{Se}_{6}(\mathrm{M}=\mathrm{Ga} / \mathrm{Sn}$, $\mathrm{In} / \mathrm{Sn})$. Interestingly, compared with the non-phase-matchable (NPM) parent $\mathrm{CsM}_{9} \mathrm{Se}_{12}$, they exhibit the desired phase-matchable (PM) behaviour and good NLO properties. ${ }^{65}$ In this study, we extended the systematic exploratory synthesis to the substitutional flexibility based on the 3D DLF and the other filled alkali metals, resulting in the discovery of two new NCS members in this family, namely $\mathrm{RbXSn}_{2} \mathrm{Se}_{6}$ (X $=\mathrm{Ga}$ and In). Significantly, they showed excellent NLO performances with a desired balance between their large SHG efficiencies (4.2 and $4.8 \times$ benchmark AGS) and large LIDTs $(8.9$ and $8.1 \times$ benchmark AGS), demonstrating that the title compounds meet the crucial conditions as promising MFIR NLO candidates.

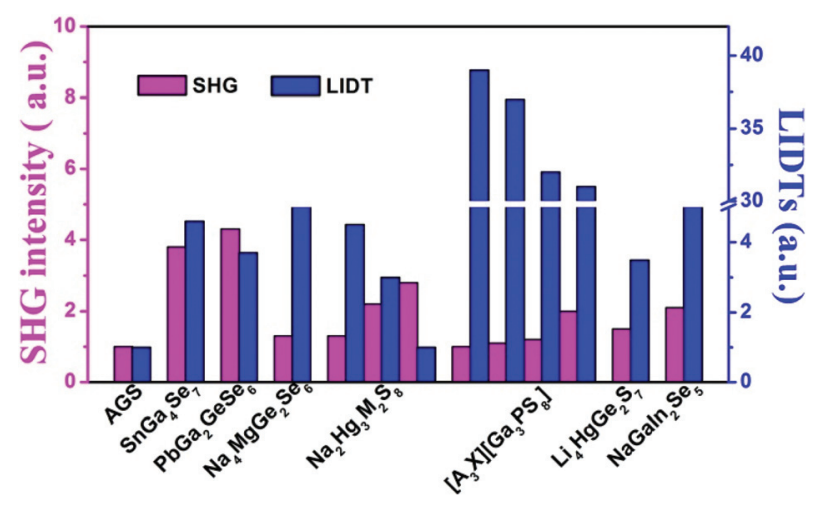

Fig. 1 Comparison of the properties in a series of outstanding MFIR $\mathrm{NLO}$ chalcogenides and $\mathrm{AgGaS}_{2}$ (AGS) as the reference.
Furthermore, the crystal structures, synthesis and theoretical analysis as well as optical properties are presented herein.

\section{Experimental}

\section{Syntheses}

The following reactant was used as purchased and stored in a glovebox filled with purified Ar (where the moisture and oxygen level was less than $0.1 \mathrm{ppm}$ ), and all the manipulations were performed inside the glovebox. Pure phases of the title compounds were synthesized by a solid-state reaction technique. Based on a large number of explorations on the experimental conditions, including changing the annealing temperature, starting reactant and loading ratio, the optimal synthesis route was determined as following: the mixture of $\mathrm{RbCl}(3 \mathrm{~N})$, $\mathrm{X}(\mathrm{X}=\mathrm{Ga}$ or In, $5 \mathrm{~N}), \mathrm{Sn}(5 \mathrm{~N})$ and Se $(5 \mathrm{~N})$ in the molar ratio of $2 / 1.5 / 1.625 / 6$ was placed into fused-silica tubes under vacuum, and annealed at $973 \mathrm{~K}$ for $50 \mathrm{~h}$, and then kept at this temperature for $100 \mathrm{~h}$, followed by slow cooling at $3 \mathrm{~K} \mathrm{~h}^{-1}$ to $473 \mathrm{~K}$, at which point the furnace was turned off. The raw products were washed with distilled water and then dried with ethanol. Deepred crystals in the millimetre size were obtained (see Fig. S1 in ESI $\dagger$ ). Analyses of these compounds with an EDX-equipped JSM6700F FESEM showed the presence of Rb, X, Sn and Se in a ratio of $1: 1: 2: 6$, but no other elements (see Fig. S2 in the $\left.\mathrm{ESI}^{\dagger}\right)$. The homogeneous target products were then analyzed using a Rigaku DMAX 2500 diffractometer with $\mathrm{Cu}-\mathrm{K} \alpha$ radiation (see Fig. 2). The title compounds were stable in air for more than 5 months.

\section{Property characterizations}

The solid-state optical absorption spectra were obtained at room temperature using a PerkinElmer Lambda $950 \mathrm{UV}-\mathrm{Vis}$ spectrophotometer. The thermal stability analyses were measured on a NETZSCH STA 449C simultaneous analyser.

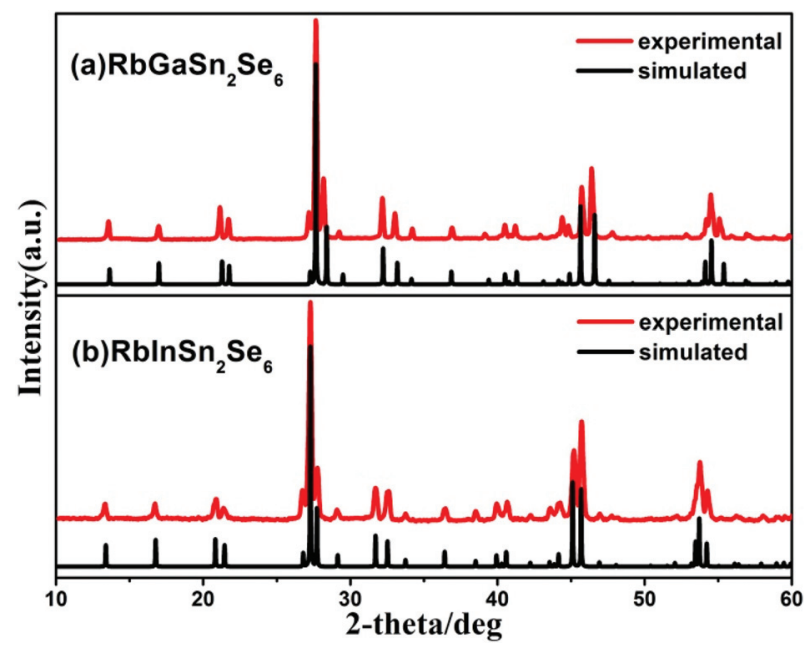

Fig. 2 Experimental (red) and simulated (black) PXRD patterns of (a) $\mathrm{RbGaSn}_{2} \mathrm{Se}_{6}$ and (b) RblnSn${ }_{2} \mathrm{Se}_{6}$. 
Powder SHG measurements were performed on a modified Kurtz-NLO system ${ }^{66}$ using $2.05 \mu \mathrm{m}$ laser radiation and the particle size of the title compounds and $\mathrm{AgGaS}_{2}$ (as a reference) ranged from 30-210 $\mu \mathrm{m}$ for the measurement, which was carried out as described elsewhere. ${ }^{60-65}$ The single-pulse measurement method was used to evaluate the powder LIDTs of the polycrystalline title compounds with a $\mathrm{AgGaS}_{2}$ single crystal as the reference $\left(1 \times 1 \times 2 \mathrm{~cm}^{3}\right.$ single crystals supplied from the Anhui Institute of Optics and Fine Mechanics Chinese Academy of Sciences). Each sample was sieved in the size range of 150-210 $\mu \mathrm{m}$, and packed into a plastic holder (diameter: $8 \mathrm{~mm}$ ) with a thickness of about $1 \mathrm{~mm}$. After irradiation by a high-power $1064 \mathrm{~nm}$ laser with a pulse width $\tau \mathrm{p}$ of $8 \mathrm{~ns}$, apparent changes of the sample were monitored using an optical microscope. The power of the laser beam was measured by a Nova II sensor with a PE50-DIF-C energy sensor, and the size of the damage spot was measured by a Vernier calliper.

\section{Single-crystal X-ray diffraction (XRD)}

Single-crystal $\mathrm{XRD}$ at room temperature was collected on a Mercury 70 CCD diffractometer with Mo $\mathrm{K} \alpha$ radiation. Absorption correction was carried out ${ }^{67}$ and the structures were solved by direct methods and refined using the SHELX-97 software. ${ }^{68}$ The structural refinement was performed with a similar method as that for the $\mathrm{BaGa}_{2} \mathrm{SnSe}_{6}$ compound, ${ }^{35}$ with the difference that the $\mathrm{X}(\mathrm{X}=\mathrm{Ga}$ or $\mathrm{In})$ and $\mathrm{Sn}$ atoms were constrained to share the same crystallographic site. During the refinement, the occupancies were restricted by using "EXYZ" and "EADP" commands in SHELX with a fixed X:Sn ratio of $1: 2$ to keep the charge balance. The $\mathrm{X}: \mathrm{Sn}$ ratio was also supported by the EDX results. The good matching of the experimental and simulated PXRD patterns together with the observed strong SHG intensity substantiated that the $R 3$ space group was correct. The refinement data are listed in Tables 1 and $\mathrm{S} 1-2 . \dagger$

Table 1 Crystallographic data and refinement details for $\mathrm{RbXSn}_{2} \mathrm{Se}_{6}$ $(\mathrm{X}=\mathrm{Ga}$ and $\mathrm{In})$

\begin{tabular}{lll}
\hline Formula & $\mathrm{RbGaSn}_{2} \mathrm{Se}_{6}$ & $\mathrm{RbInSn}_{2} \mathrm{Se}_{6}$ \\
\hline fw & 866.33 & 911.43 \\
Crystal system & Trigonal & Trigonal \\
Crystal colour & Deep-red & Deep-red \\
Space group & $R 3$ (no. 146) & $R 3$ (no. 146) \\
$a(\AA)$ & $10.4697(2)$ & $10.6044(8)$ \\
$c(\AA)$ & $9.476(2)$ & $9.660(2)$ \\
$V\left(\AA^{3}\right)$ & $899.5(3)$ & $940.7(2)$ \\
$Z$ & 3 & 3 \\
$D_{\mathrm{c}}\left(\mathrm{g} \mathrm{cm}^{-3}\right)$ & 4.798 & 4.832 \\
$R_{\text {int }}$ & 0.0349 & 0.0326 \\
$\mu\left(\mathrm{mm}^{-1}\right)$ & 28.54 & 26.98 \\
$\mathrm{GOOF}$ on $F^{2}$ & 1.025 & 1.015 \\
$R_{1}, \mathrm{w} R_{2}(I>2 \sigma(I))^{a}$ & $0.0228,0.0400$ & $0.0254,0.0483$ \\
$R_{1}, \mathrm{w} R_{2}($ all data) & $0.0244,0.0402$ & $0.0274,0.0487$ \\
Largest diff. peak and hole $\left(\mathrm{e} \AA^{-3}\right)$ & $0.807,-0.903$ & $1.145,-1.010$ \\
${ }^{a} R_{1}=\sum|| F_{\mathrm{o}}|-| F_{\mathrm{c}}|| \sum\left|F_{\mathrm{o}}\right|, \mathrm{w} R_{2}=\left[\sum \mathrm{w}\left(F_{\mathrm{o}}{ }^{2}-F_{\mathrm{c}}{ }^{2}\right)^{2} / \sum \mathrm{w}\left(F_{\mathrm{o}}{ }^{2}\right)^{2}\right]^{1 / 2}$.
\end{tabular}

\section{Computational sections}

Theoretical studies were performed by $\mathrm{DFT}^{69 a}$ with the generalized gradient approximation $(\mathrm{GGA})^{69 b}$ as implemented in the VASP. ${ }^{69 c}$ The plane-wave basis set with projector augmented wave (PAW) ${ }^{69 d, e}$ potentials was used to represent the core electrons. The plane-wave cut-off energy of $600 \mathrm{eV}$ was chosen for all the calculations and denser $\kappa$-point grids of $0.02 \AA^{-1}$ were utilized in the optical property calculations. According to the single-crystal structure refinement results, $\mathrm{X}$ and $\mathrm{Sn}$ atoms share the $9 b$ Wyckoff sites $\mathrm{M}$ with an $\mathrm{X}$ occupancy of about $1 / 3$, and therefore, in total, 12 possible models were designed. ${ }^{70}$ The calculation model was built in the most energetically favourable manner. For calculating the optical properties, scissors operators were applied for the title compounds and $\mathrm{AgGaS}_{2}$ (AGS). The second-order nonlinear susceptibility $\chi^{a b c}(-2 \omega, \omega, \omega)$ was calculated through the so-called lengthgauge formalism. ${ }^{71}$ The calculation model and specific parameter settings were as described in our previously reported paper. $^{65}$

\section{Results and discussion}

\section{Crystal structure}

The single-crystal XRD data revealed that the title compounds are uniaxial crystals and crystallize in the NCS polar trigonal space group $R 3$ (no. 146, Person symbol $h R 10$ ) with $a=10.4697$ (2) $\AA$, $c=9.476(2) \AA$ and $Z=3$ for $\operatorname{RbGaSn}_{2} \mathrm{Se}_{6}$, and $a=10.6044(8)$ $\AA$, $c=9.660(2) \AA$ and $Z=3$ for $\mathrm{RbInSn}_{2} \mathrm{Se}_{6}$, which belong to the $\mathrm{BaGa}_{2} \mathrm{SnSe}_{6}$-structure type. ${ }^{35}$ In the asymmetric unit, there is one crystallographic $\mathrm{Rb}$ atom (Wyckoff site, $3 a$ ) and one $\mathrm{M}$ position (Wyckoff site, 9b) randomly occupied by both $\mathrm{Ga} / \mathrm{In}$ and $\mathrm{Sn}$ in the molar ratio of $1: 2$, and two Se atoms (Wyckoff sites, $9 b$ and $9 b$ ), as listed in Table S1. $\uparrow$ The remarkable structures of the 3D diamond-like frameworks (DLFs) are formed by the tri-nuclear secondary basic structure unit $\left[\mathrm{M}_{3} \mathrm{Se}_{9}\right](\mathrm{M}=$ $\mathrm{X} / \mathrm{Sn}$ ), which is constructed with three vertex-sharing $\left[\mathrm{MSe}_{4}\right]$ tetrahedra (see Fig. 3a and b). The normal M-Se distances of 2.4796(9)-2.5471(9) А (see Table S2 in the ESI $\dagger$ ) are consistent with those of $\mathrm{BaGa}_{2} \mathrm{SnSe}_{6}$ (M-Se: 2.35570(7)-2.4501(7) $\AA$ ), ${ }^{35}$ $\mathrm{CsGaSn}_{2} \mathrm{Se}_{6}$ (M-Se: 2.4812(6)-2.4949(8) $)^{65}$ and $\mathrm{CsInSn}_{2} \mathrm{Se}_{6}$ (M-Se: $2.5408(7)-2.5493(8) \AA) .{ }^{65}$ Furthermore, the Rb atom fills with 3D DLFs (Fig. 3a) and centres the $\mathrm{Se}_{12}$ cuboctahedron (Fig. 3c). The Rb-Se interatomic distances vary from 3.8290(9) to 3.9462 (8) $\AA$, which are a little longer than those observed in related compounds, such as $\mathrm{RbCd}_{4} \mathrm{Ga}_{5} \mathrm{Se}_{12}$ (3.804(2)-3.864(9) A), ${ }^{61} \mathrm{RbCd}_{4} \operatorname{In}_{5} \mathrm{Se}_{12}(3.872(2)-3.915(8) \AA)^{61}$ and $\mathrm{RbMn}_{4} \mathrm{In}_{5} \mathrm{Se}_{12}$ (3.872(8)-3.901(2) ̊). ${ }^{61}$ Besides, it should be emphasized that the identity of the alkali metal on going from $\mathrm{Rb}^{+}$to $\mathrm{Cs}^{+}$does not significantly affect the 3D DLF structures, but increases the NLO property of this family of compounds, as discussed below.

\section{Optical properties and thermal stabilities}

According to the solid-state diffuse-reflectance UV-vis/near-IR spectra at room temperature, the results show that the poly- 


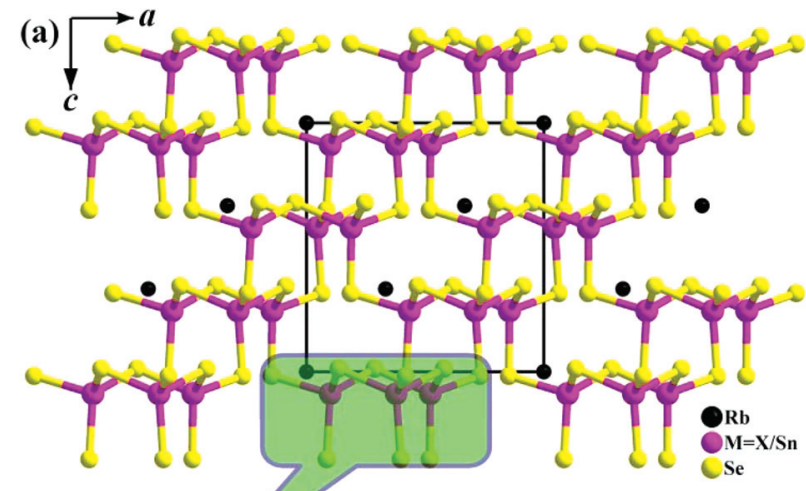

(b)
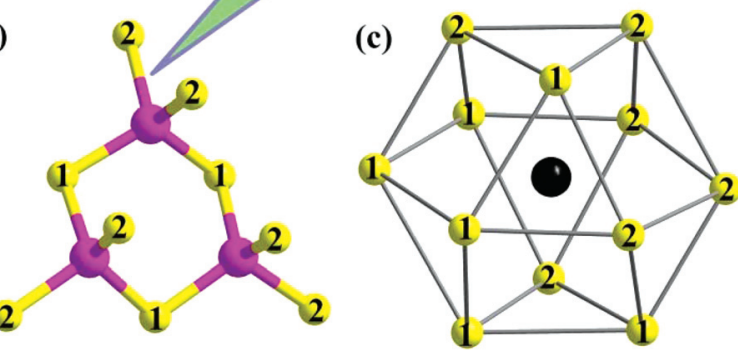

Fig. 3 (a) 3D DLF structure of $\mathrm{RbXSn}_{2} \mathrm{Se}_{6}$ viewed down the $b$-direction with the unit cell marked. (b) The tri-nuclear secondary basic structure unit $\left[\mathrm{M}_{3} \mathrm{Se}_{9}\right](\mathrm{M}=\mathrm{X} / \mathrm{Sn})$, with the Se atom numbers marked, is outlined by the green shadow in (a). (c) View of the $\mathrm{Rb}$-centred $\mathrm{Se}_{12}$ cuboctahedron.

crystalline title compounds possess semiconducting band gaps of $1.80 \mathrm{eV}$ (for $\mathrm{RbGaSn}_{2} \mathrm{Se}_{6}$ ) and $1.92 \mathrm{eV}$ (for $\mathrm{RbInSn}_{2} \mathrm{Se}_{6}$ ), which are consistent with their deep-red colours (Fig. 4). The TG-DTA measurement results of the title compounds in nitrogen are shown in Fig. S3. $\dagger$ As can be seen, the thermal stabilities of the title compounds can be up to $966 \mathrm{~K}$ (for $\mathrm{RbGaSn}_{2} \mathrm{Se}_{6}$ ) and $951 \mathrm{~K}$ (for $\mathrm{RbInSn}_{2} \mathrm{Se}_{6}$ ), and furthermore, the endothermic peak indicates that these compounds de-

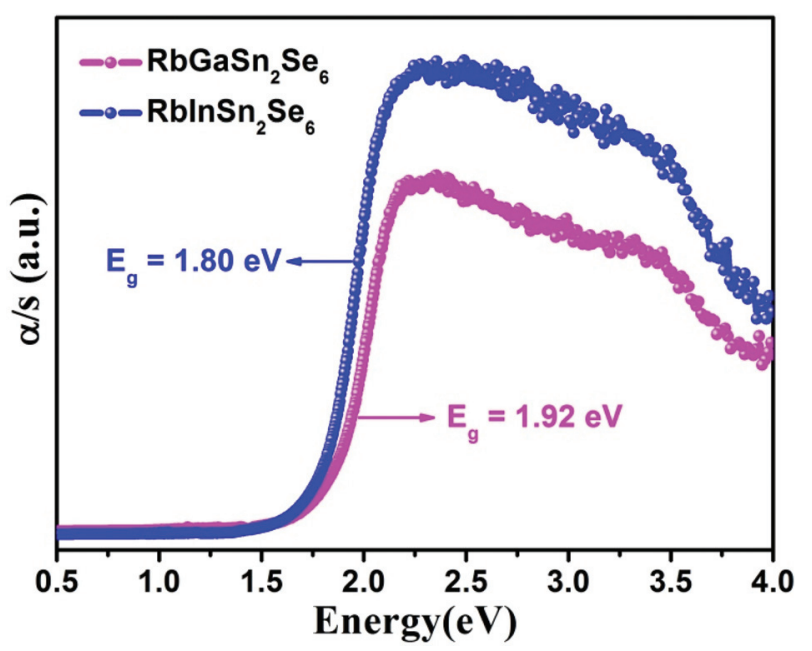

Fig. 4 Solid-state UV-vis optical absorption spectra of $\mathrm{RbGaSn}_{2} \mathrm{Se}_{6}$ and $\mathrm{Rb}_{\operatorname{lnSn}} \mathrm{Se}_{6}$. compose after this temperature. This is in accordance with the PXRD analysis (detailed information is given in Fig. S4 $\dagger$ ), and such similar examples are also observed in the $\mathrm{CsXSn}_{2} \mathrm{Se}_{6}(\mathrm{X}=$ Ga, In) compounds. ${ }^{65}$

\section{NLO properties and powder LIDTs}

The NLO properties of the title compounds were studied due to the NCS polar space group 23 . The powder SHG of $\mathrm{RbGaSn}_{2} \mathrm{Se}_{6}$ and $\mathrm{RbGaSn}_{2} \mathrm{Se}_{6}$ were investigated with a $2050 \mathrm{~nm}$ Q-switch laser and using $\mathrm{AgGaS}_{2}$ as the ref. 66. The particle size versus the SHG intensity curve is illustrated in Fig. 5a. The SHG intensities of the title compounds increased with the increasing particle size, with the peak realized at the particle size of 150-210 $\mu \mathrm{m}$ indicating a PM nature. ${ }^{59}$ Remarkably, the powder SHG intensities of $\mathrm{RbGaSn}_{2} \mathrm{Se}_{6}$ and $\mathrm{RbGaSn}_{2} \mathrm{Se}_{6}$ were 4.2 and 4.8 times that of the reference $\mathrm{AgGaS}_{2}$ at the same particle size, respectively (Fig. 5b, pink bar). More importantly, $\mathrm{RbInSn}_{2} \mathrm{Se}_{6} \quad$ represents the second strongest powder SHG among the state-of-the-art PM chalcogenides reported to date. Powder LIDT data of the title compounds and benchmark $\mathrm{AgGaS}_{2}$ were collected using the single-pulse powder LIDT method. ${ }^{28}$ As illustrated in Fig. $5 \mathrm{~b}$ and Table 2 , the title compounds show high LIDTs at an incident laser of $1064 \mathrm{~nm}$, namely $12.82,11.66 \mathrm{MW} \mathrm{cm}{ }^{-2}$, which are estimated to be 8.9 and 8.1 times greater than that of the benchmark
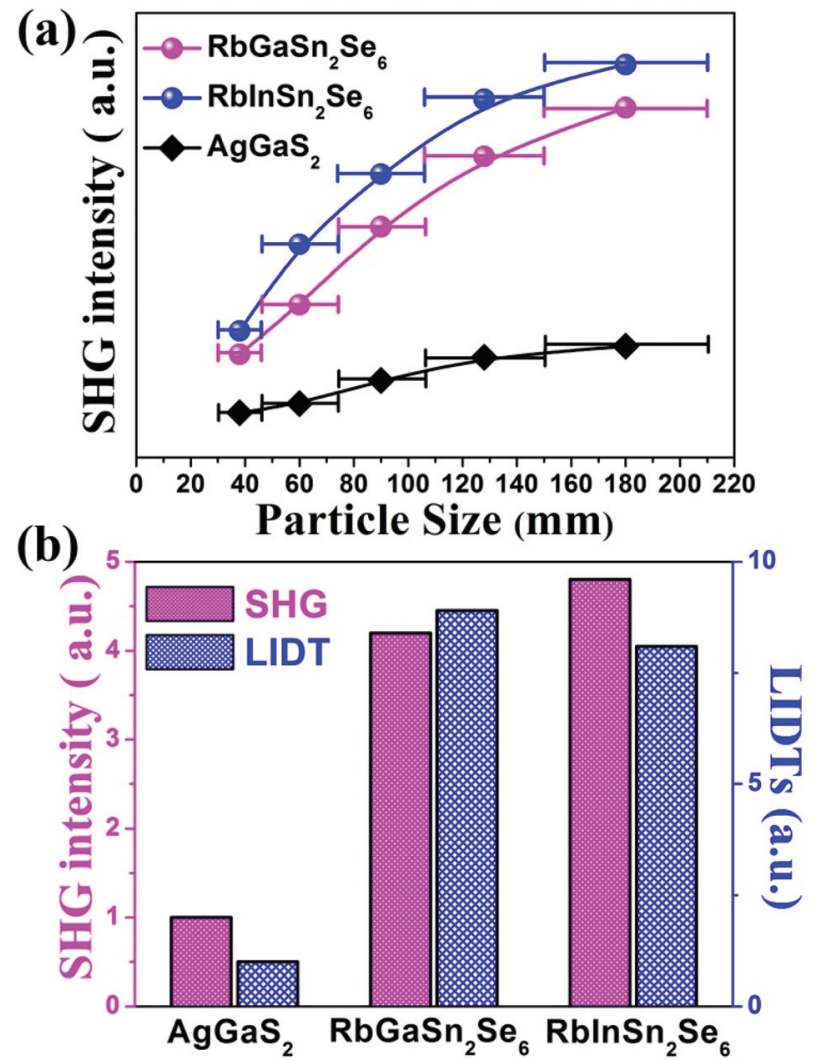

Fig. 5 (a) Particle size vs. SHG intensity curves for the title compounds and $\mathrm{AgGaS}_{2}$ (reference). (b) The relative SHG and LIDT intensities of the title compounds and $\mathrm{AgGaS}_{2}$ in the particle size of $150-210 \mu \mathrm{m}$. 
Table 2 Comparison of the properties of the title compounds and benchmark $\mathrm{AgGaS}_{2}$

\begin{tabular}{llll}
\hline & $\mathrm{RbGaSn}_{2} \mathrm{Se}_{6}$ & $\mathrm{RbInSn}_{2} \mathrm{Se}_{6}$ & $\mathrm{AgGaS}_{2}$ \\
\hline${\text { SHG coefficient } d_{i j}{ }^{a}}$ & $d_{11}=43.9$ & $d_{11}=48.8$ & $d_{36}=18.2$ \\
& $d_{15}=51.5$ & $d_{15}=60.2$ & \\
& $d_{22}=23.7$ & $d_{22}=29.3$ & \\
& $d_{33}=26.3$ & $d_{33}=20.4$ & \\
${\text { Band-gap }\left(E_{\mathrm{g}} / \mathrm{eV}\right)^{b}}_{\text {Birefringence }^{a}}$ & 1.92 & 1.80 & 2.56 \\
Powder SHG intensities $^{c}$ & 0.051 & 0.067 & 0.039 \\
Powder LIDTs $_{\left(\mathrm{MW} / \mathrm{cm}^{2}\right)^{c}}$ & $1.2 \times$ AGS & $4.8 \times$ AGS & AGS \\
& $(8.9 \times$ AGS $)$ & $(8.1 \times$ AGS) & (AGS)
\end{tabular}

${ }^{a}$ Calculated at $2050 \mathrm{~nm}$. ${ }^{b}$ Measured on ground polycrystalline samples. ${ }^{c}$ Measured in the particle size range $150-210 \mu \mathrm{m}$.

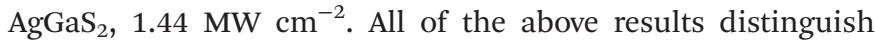
$\operatorname{RbGaSn}_{2} \mathrm{Se}_{6}(\mathrm{X}=\mathrm{Ga}$, In) as one of the best MFIR NLO materials known to date.

In the $\mathrm{AInSn}_{2} \mathrm{Se}_{6}(\mathrm{~A}=\mathrm{Rb}, \mathrm{Cs})$ compounds, it is noteworthy that the ionic nature of the alkali metal cations does not affect the overall polarity of the structure but significantly affects the SHG and LIDT performances. Taking $\mathrm{AInSn}_{2} \mathrm{Se}_{6}$ as an example, the ionic radii only decrease about $8.5 \%$ from $\mathrm{Cs}^{+}$to $\mathrm{Rb}^{+}\left(r_{\mathrm{Cs}^{+}}=1.88 \AA\right.$ and $r_{\mathrm{Rb}^{+}}=1.72 \AA$ for $\mathrm{CN}=12$, respectively), while the powder SHG intensity increase $20 \%(4.0 \times$ AGS $v s$. $4.8 \times$ AGS for $\mathrm{CsInSn}_{2} \mathrm{Se}_{6}$ and $\mathrm{RbInSn}_{2} \mathrm{Se}_{6}$, respectively) and the LIDT decrease 14\% (9.2 $\times$ AGS vs. $8.1 \times$ AGS for $\mathrm{CsInSn}_{2} \mathrm{Se}_{6}$ and $\mathrm{RbInSn}_{2} \mathrm{Se}_{6}$, respectively). A similar trend has been seen in some other alkali metal-containing chalcogenides, e.g. $\mathrm{A}_{4} \mathrm{GeP}_{4} \mathrm{Se}_{12}{ }^{25}$ and $\mathrm{AM}_{9} \mathrm{Se}_{12} \cdot{ }^{60-64}$

\section{Theoretical studies}

In order to understand the structure-property relationship of the title compounds, the linear and nonlinear optical properties were studied with the aid of the $a b$ initio calculations performed by VASP software. The electronic band structures indicated direct band gaps of 1.51 and $1.26 \mathrm{eV}$ for $\mathrm{RbGaSn}_{2} \mathrm{Se}_{6}$ and $\mathrm{RbGaSn}_{2} \mathrm{Se}_{6}$, respectively (Fig. S5 in ESI $\dagger$ ). Such a discrepancy was likely due to a common problem that occurs with GGA calculations. ${ }^{72}$ As shown in Fig. 6a, the calculated densities of states (DOSs) of the title compounds with the main contributions are similar near the Fermi level. In addition, the origin of the SHG response (Fig. S6 in the ESI†) and the cut-off energy dependence of the largest secondorder tensor $d_{15}$ were also investigated. Fig. 6b shows that in the regions of VB-1 (dominated by the Se-4p and Sn-5p orbitals) and CB-2 (dominated by the Se-4p, Sn-5s and Ga(In)$\mathrm{ns} / \mathrm{np}$ orbitals), the $d_{15}$ values are the most sharply increased, which contributes mainly to the second-order NLO susceptibility. In other words, the NLO activities of the title compounds originate from the condensation of the $\mathrm{MSe}_{4}(\mathrm{M}=\mathrm{Ga}$, In) tetrahedral units that built the $3 \mathrm{D}$ DLF structures. The calculated $d_{15}$ values of $\mathrm{RbGaSn}_{2} \mathrm{Se}_{6}$ and $\mathrm{RbGaSn}_{2} \mathrm{Se}_{6}$ were 51.5 and $60.2 \mathrm{pm} \mathrm{V}^{-1}$ at the wavelength of $2.05 \mu \mathrm{m}$ (i.e. $0.61 \mathrm{eV}$ ), respectively. These values were 2.8 and 3.3 times larger than
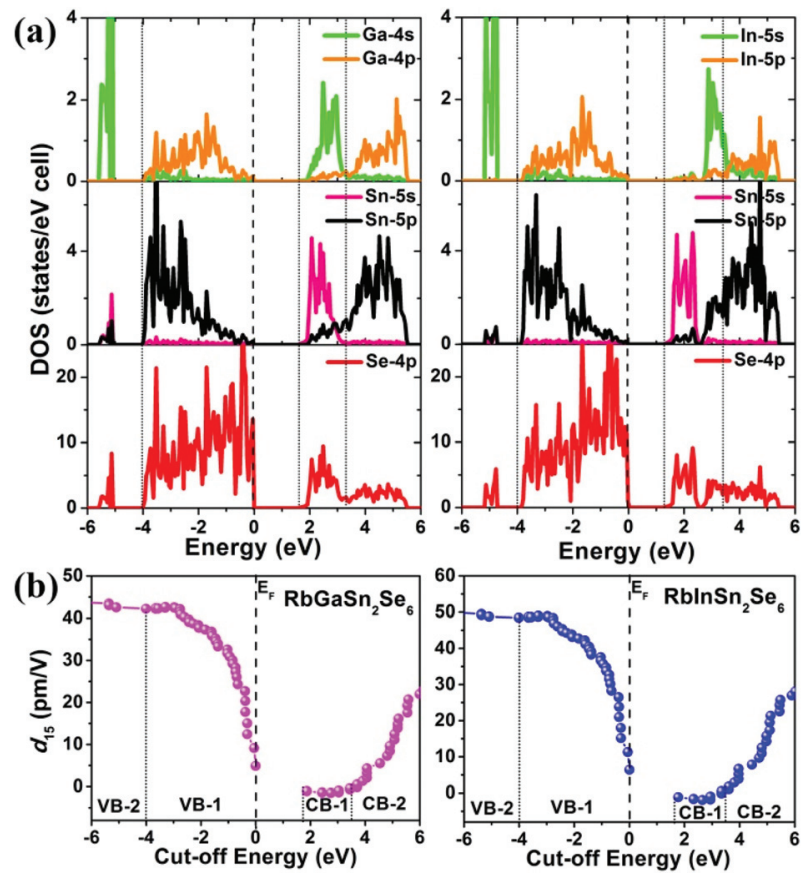

Fig. 6 (a) DOSs of $\mathrm{RbXSn}_{2} \mathrm{Se}_{6}(\mathrm{X}=\mathrm{Ga}$, In) (the orbitals with minor contributions are omitted for clarity). (b) Static SHG coefficients of $\mathrm{RbXSn}_{2} \mathrm{Se}_{6}(\mathrm{X}=\mathrm{Ga}, \mathrm{In})$ as a function of the cut-off energy. Dashed line, $E_{\mathrm{F}}$; dotted line, different regions in the valence bands (VB) and conduction bands (CB).

that of $\mathrm{AgGaS}_{2}\left(d_{36}=18.2 \mathrm{pm} \mathrm{V}^{-1}\right)$ at the same wavelength (Fig. 7) and were close to the experimental measurements (4.2 or 4.8 times stronger than $\mathrm{AgGaS}_{2}$ at the range 150-210 $\mu \mathrm{m}$, see Fig. 5).

As shown in Fig. 8, the calculated birefringence $(\Delta n)$ values of $\mathrm{RbGaSn}_{2} \mathrm{Se}_{6}$ and $\mathrm{RbInSn}_{2} \mathrm{Se}_{6}$ are 0.051 and 0.067 at the wavelength of $2050 \mathrm{~nm}(0.61 \mathrm{eV})$, respectively, both of which are larger than that of $\mathrm{AgGaS}_{2}(0.039)$ and are in an optimal

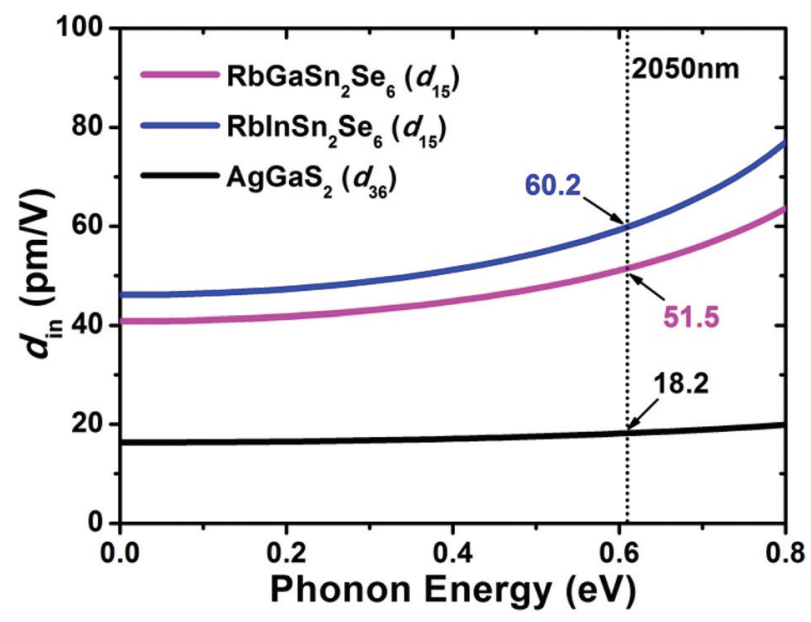

Fig. 7 Calculated frequency-dependent SHG coefficients for $\mathrm{RbXSn}_{2} \mathrm{Se}_{6}\left(\mathrm{X}=\mathrm{Ga}\right.$, In) and $\mathrm{AgGaS}_{2}$ (reference). 


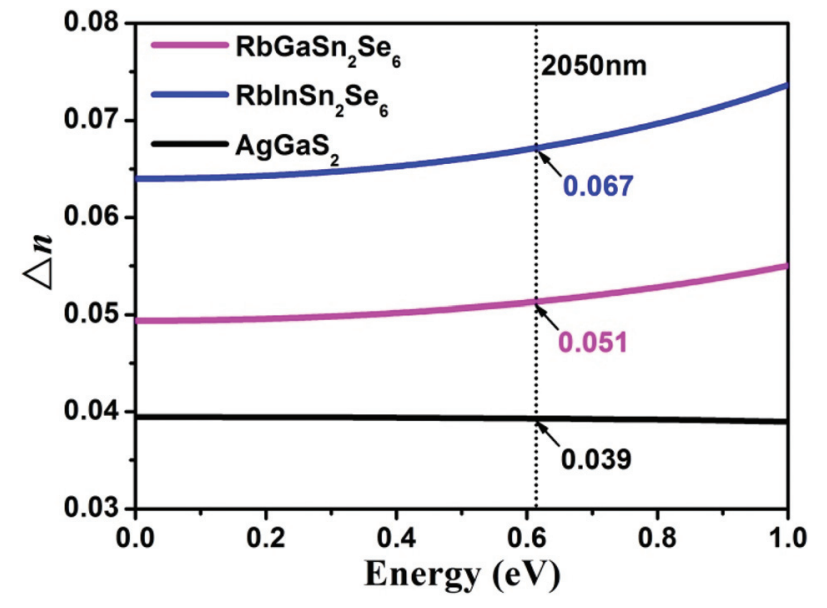

Fig. 8 Calculated birefringence $(\Delta n)$ of $\mathrm{RbXSn}_{2} \mathrm{Se}_{6}(X=G a, I n)$ and $\mathrm{AgGaS}_{2}$ (reference).

range $(0.04<\Delta n<0.10),{ }^{8}$ indicating that the title compounds can easily achieve the PM feature in the MFIR range. Such results are similar to those of the Cs-members in this family ${ }^{65}$ and better than $\mathrm{BaGa}_{2} \mathrm{XSe}_{6}(\mathrm{X}=\mathrm{Si}, \mathrm{Ge}, \mathrm{Sn})$ at the same wavelength $(\Delta n>0.10),{ }^{26,35}$ because having too large a $\Delta n$ will cause issues with two main drawbacks: walk-off effects and self-focus in the conversion process. ${ }^{8}$ Besides, several key parameters are summarized in Table 2, indicating that the title compounds satisfy the key requirements needed as promising MFIR NLO candidates.

\section{Conclusions}

In summary, two new quaternary NLO-active selenides, $\mathrm{RbXSn}_{2} \mathrm{Se}_{6}(\mathrm{X}=\mathrm{Ga}$, In), were discovered using the reactive flux method. They crystallized in the polar space group $R 3$ and their structures exhibited a 3D diamond-like framework (DLF) composed of $\mathrm{MSe}_{4}(\mathrm{M}=\mathrm{X} / \mathrm{Sn})$ units that were stacked up by sharing common Se atoms. Remarkably, they displayed excellent NLO performances with concurrently strong SHG efficiencies and large LIDTs, as well as phase-matching features. In particular, $\mathrm{RbInSn}_{2} \mathrm{Se}_{6}(4.8 \times \mathrm{AGS})$ represents the second strongest powder SHG among the state-of-the-art chalcogenides reported to date in the particle size 150-210 $\mu \mathrm{m}$. DFT studies were carried out to aid the understanding of the electronic structures and linear and NLO properties. Moreover, the title compounds showed other essential requirements as promising MFIR NLO materials, including a moderate optical birefringence $(\Delta n=0.051$ and 0.067$)$ and good thermal stability (up to $950 \mathrm{~K})$. All these results indicate that the title compounds can be good candidates for MFIR NLO materials. Follow-on efforts to grow large-size crystals are in progress. Furthermore, based upon analyzing their structure-property relationship, this new type of 3D DLF structure represents an unprecedented opportunity for the rational design and development of excellent MFIR NLO materials.

\section{Acknowledgements}

This work was supported by the NSF of China (21301175, 21233009, 21571020 and 91422303) and the NSF of Fujian Province (2015J01071). We thank Professor Ge Zhang and Doctor Bing-Xuan Li (FJIRSM, CAS) for their help with NLO measurements and Professor Yong-Fan Zhang (Fuzhou University) helping with the DFT calculations.

\section{Notes and references}

1 (a) D. N. Nikogosyan, Nonlinear Optical Crystals: A Complete Survey, Springer-Science, New York, 2005; (b) StructureProperty Relationships in Nonlinear Optical Crystals II The IR Region, in Structure and Bonding, ed. X.-T. Wu and L. Chen, Series ed. D. M. Mingos, Springer, New York, 2012, vol. 145; (c) I. Chung and M. G. Kanatzidis, Chem. Mater., 2014, 26, 849-869; (d) C. L. Hu and J. G. Mao, Coord. Chem. Rev., 2015, 288, 1-17; (e) Y. Wang and S. L. Pan, Coord. Chem. Rev., 2016, 323, 15-35; (f) F. Liang, L. Kang, Z. S. Lin, Y. C. Wu and C. T. Chen, Coord. Chem. Rev., 2017, 333, 57-70; (g) S. P. Guo, Y. Chi and G. C. Guo, Coord. Chem. Rev., 2017, 335, 44-57.

2 C. T. Chen, Y. C. Wu, A. D. Jiang, B. Wu, G. M. You, R. K. Li and S. J. Lin, J. Opt. Soc. Am. B, 1989, 6, 616-621.

3 C. T. Chen, B. C. Wu, A. D. Jiang and G. M. You, Sci. Sin., Ser. B, 1985, 28, 235-243.

4 J. F. Ward and P. A. Franken, Phys. Rev., 1964, 133, A183A190.

5 K. Kato, IEEE J. Quantum Electron., 1991, 27, 1137-1140.

6 (a) Y. N. Xia, C. T. Chen, D. Y. Tang and B. C. Wu, Adv. Mater., 1995, 7, 79-81; (b) D. Cyranoski, Nature, 2009, 457, 953-955.

7 (a) A. Harasaki and K. J. Kato, Appl. Phys., 1997, 36, 700703; (b) G. C. Catella, L. R. Shiozawa, J. R. Hietanen, R. C. Eckardt, R. K. Route, R. S. Feigelson, D. G. Cooper and C. L. Marquardt, Appl. Opt., 1993, 32, 3948-3951; (c) G. D. Boyd, E. Buehler and F. G. Storz, Appl. Phys. Lett., 1971, 18, 301-304.

8 L. Kang, M. L. Zhou, J. Y. Yao, Z. S. Lin, Y. C. Wu and C. T. Chen, J. Am. Chem. Soc., 2015, 137, 1304913059.

9 I. Chung, C. D. Malliakas, J. I. Jang, C. G. Canlas, D. P. Weliky and M. G. Kanatzidis, J. Am. Chem. Soc., 2007, 129, 14996-15006.

10 X. S. Lin, G. Zhang and N. Ye, Cryst. Growth Des., 2009, 9, 1186-1189.

11 T. K. Bera, J. I. Jang, J. B. Ketterson and M. G. Kanatzidis, J. Am. Chem. Soc., 2009, 131, 75-77.

12 S. Banerjee, C. D. Malliakas, J. I. Jang, J. B. Ketterson and M. G. Kanatzidis, J. Am. Chem. Soc., 2008, 130, 1227012272.

13 I. Chung, J. H. Song, J. I. Jang, A. J. Freeman, J. B. Ketterson and M. G. Kanatzidis, J. Am. Chem. Soc., 2009, 131, 2647-2656. 
14 Q. C. Zhang, I. Chung, J. I. Jang, J. B. Ketterson and M. G. Kanatzidis, J. Am. Chem. Soc., 2009, 131, 98969897.

15 I. Chung, J. I. Jang, C. D. Malliakas, J. B. Ketterson and M. G. Kanatzidis, J. Am. Chem. Soc., 2010, 132, 384-389.

16 T. K. Bera, J. I. Jang, J. H. Song, C. D. Malliakas, A. J. Freeman, J. B. Ketterson and M. G. Kanatzidis, J. Am. Chem. Soc., 2010, 132, 3484-3495.

17 S. Banerjee, J. M. Szarko, B. D. Yuhas, C. D. Malliakas, L. X. Chen and M. G. Kanatzidis, J. Am. Chem. Soc., 2010, 132, 5348-5350.

18 J. Y. Yao, D. J. Mei, L. Bai, Z. S. Lin, W. L. Yin, P. Z. Fu and Y. C. Wu, Inorg. Chem., 2010, 49, 9212-9216.

19 X. M. Jiang, M. J. Zhang, H. Y. Zeng, G. C. Guo and J. S. Huang, J. Am. Chem. Soc., 2011, 133, 3410-3418.

20 M. C. Chen, L. H. Li, Y. B. Chen and L. Chen, J. Am. Chem. Soc., 2011, 133, 4617-4624.

21 H. J. Zhao, Y. F. Zhang and L. Chen, J. Am. Chem. Soc., 2012, 134, 1993-1995.

22 P. Yu, L. J. Zhou and L. Chen, J. Am. Chem. Soc., 2012, 134, 2227-2235.

23 M. C. Chen, L. M. Wu, H. Lin, L. J. Zhou and L. Chen, J. Am. Chem. Soc., 2012, 134, 6058-6060.

24 G. Zhang, Y. J. Li, K. Jiang, H. Y. Zeng, T. Liu, X. G. Chen, J. G. Qin, Z. S. Lin, P. Z. Fu, Y. C. Wu and C. T. Chen, J. Am. Chem. Soc., 2012, 134, 14818-14822.

25 C. D. Morris, I. Chung, S. Park, C. M. Harrison, D. J. Clark, J. I. Jang and M. G. Kanatzidis, J. Am. Chem. Soc., 2012, 134, 20733-20744.

26 W. L. Yin, K. Feng, R. He, D. J. Mei, Z. S. Lin, J. Y. Yao and Y. C. Wu, Dalton Trans., 2012, 41, 5653-5661.

27 L. Kang, D. M. Ramo, Z. S. Lin, P. D. Bristowe, J. G. Qin and C. T. Chen, J. Mater. Chem. C, 2013, 1, 7363-7370.

28 M. J. Zhang, X. M. Jiang, L. J. Zhou and G. C. Guo, J. Mater. Chem. C, 2013, 1, 4754-4760.

29 Q. Wu, X. G. Meng, C. Zhong, X. G. Chen and J. G. Qin, J. Am. Chem. Soc., 2014, 136, 5683-5686.

30 Z. Z. Luo, C. S. Lin, W. L. Zhang, H. Zhang, Z. Z. He and W. D. Cheng, Chem. Mater., 2014, 26, 1093-1099.

31 Z. Z. Luo, C. S. Lin, H. H. Cui, W. L. Zhang, H. Zhang, Z. Z. He and W. D. Cheng, Chem. Mater., 2014, 26, 27432749.

32 J. A. Brant, D. J. Clark, Y. S. Kim, J. I. Jang, J. H. Zhang and J. A. Aitken, Chem. Mater., 2014, 26, 3045-3048.

33 K. Feng, L. Kang, Z. S. Lin, J. Y. Yao and Y. C. Wu, J. Mater. Chem. C, 2014, 2, 4590-4596.

34 X. S. Li, L. Kang, C. Li, Z. S. Lin, J. Y. Yao and Y. C. Wu, J. Mater. Chem. C, 2015, 3, 3060-3067.

35 X. S. Li, C. Li, P. F. Gong, Z. S. Lin, J. Y. Yao and Y. C. Wu, J. Mater. Chem. C, 2015, 3, 10998-11004.

36 J. C. Syrigos, D. J. Clark, F. O. Saouma, S. M. Clarke, L. Fang, J. I. Jang and M. G. Kanatzidis, Chem. Mater., 2015, 27, 255-265.

37 Z. Z. Luo, C. S. Lin, H. H. Cui, W. L. Zhang, H. Zhang, H. Chen, Z. Z. He and W. D. Cheng, Chem. Mater., 2015, 27, 914-922.
38 W. H. Lai, A. S. Haynes, L. Frazer, Y. M. Chang, T. K. Liu, J. F. Lin, I. C. Liang, H. S. Sheu, J. B. Ketterson, M. G. Kanatzidis and K. F. Hsu, Chem. Mater., 2015, 27, 1316-1326.

39 A. S. Haynes, F. O. Saouma, C. O. Otieno, D. J. Clark, D. P. Shoemaker, J. I. Jang and M. G. Kanatzidis, Chem. Mater., 2015, 27, 1837-1846.

40 Y. F. Shi, Y. K. Chen, M. C. Chen, L. M. Wu, H. Lin, L. J. Zhou and L. Chen, Chem. Mater., 2015, 27, 18761884.

41 J. A. Brant, D. J. Clark, Y. S. Kim, J. I. Jang, A. Weiland and J. A. Aitken, Inorg. Chem., 2015, 54, 2809-2819.

42 K. Wu, Z. H. Yang and S. L. Pan, Inorg. Chem., 2015, 54, 10108-10110.

43 L. Chao, W. L. Yin, P. F. Gong, X. S. Li, M. L. Zhou, M. Arthur, Z. S. Lin, J. Y. Yao, Y. C. Wu and C. T. Chen, J. Am. Chem. Soc., 2016, 138, 6135-6138.

44 A. S. Haynes, A. Banerjee, F. O. Saouma, C. O. Otieno, J. I. Jang and M. G. Kanatzidis, Chem. Mater., 2016, 28, 2374-2383.

45 K. Wu, Z. H. Yang and S. L. Pan, Chem. Mater., 2016, 28, 2795-2801.

46 K. Wu, Z. H. Yang and S. L. Pan, Angew. Chem., Int. Ed., 2016, 55, 6713-6715.

47 G. M. Li, K. Wu, Q. Liu, Z. H. Yang and S. L. Pan, J. Am. Chem. Soc., 2016, 138, 7422-7428.

48 B. W. Liu, H. Y. Zeng, X. M. Jiang, G. E. Wang, S. F. Li, L. Xu and G. C. Guo, Chem. Sci., 2016, 7, 6273-6277.

49 Y. Y. Li, P. F. Liu, H. Lin, M. T. Wang and L. Chen, Inorg. Chem. Front., 2016, 3, 952-958.

50 R. H. Duan, J. S. Yu, H. Lin, Y. J. Zheng, H. J. Zhao, S. X. Huang-Fu, M. A. Khan, L. Chen and L. M. Wu, Dalton Trans., 2016, 45, 12288-12291.

51 M. L. Zhou, L. Kang, J. Y. Yao, Z. S. Lin, Y. C. Wu and C. T. Chen, Inorg. Chem., 2016, 55, 3724-3726.

52 W. L. Yin, A. K. Iyer, C. Li, J. Y. Yao and A. Mar, J. Mater. Chem. C, 2017, 5, 1057-1063.

53 Y. Y. Li, J. Q. Wang, P. F. Liu, H. Lin, L. Chen and L. M. Wu, RSC Adv., 2017, 7, 8082-8089.

54 K. Wu, Z. H. Yang and S. L. Pan, Chem. Commun., 2017, 53, 3010-3013.

55 S. F. Li, X. M. Jiang, B. W. Liu, D. Yan, C. S. Lin, H. Y. Zeng and G. C. Guo, Chem. Mater., 2017, 29, 1796-1804.

56 G. M. Li, Q. Liu, K. Wu, Z. H. Yang and S. L. Pan, Dalton Trans., 2017, 46, 2778-2784.

57 P. F. Liu, Y. Y. Li, Y. J. Zheng, J. S. Yu, R. H. Duan, H. Chen, H. Lin, L. Chen and L. M. Wu, Dalton Trans., 2017, 46, 2715-2721.

58 Q. C. Zhang, I. Chung, J. I. Jang, J. B. Ketterson and M. G. Kanatzidis, Chem. Mater., 2009, 21, 12-14.

59 (a) K. M. Ok, E. O. Chi and P. S. Halasyamani, Chem. Soc. Rev., 2006, 35, 710-717; (b) E. A. Muller, R. J. Cannon, A. N. Sarjeant, K. M. Ok, P. S. Halasyamani and A. J. Norquist, Cryst. Growth Des., 2005, 5, 1913-1917.

60 H. Lin, L. J. Zhou and L. Chen, Chem. Mater., 2012, 24, 3406-3414. 
61 H. Lin, L. Chen, L. J. Zhou and L. M. Wu, J. Am. Chem. Soc., 2013, 135, 12914-12921.

62 H. Lin, Y. Liu, L. J. Zhou, H. J. Zhao and L. Chen, Inorg. Chem., 2016, 55, 4470-4475.

63 H. Lin, H. Chen, Y. J. Zheng, J. S. Yu and L. M. Wu, Dalton Trans., 2016, 45, 17606-17609.

64 H. Lin, Y. J. Zheng, H. Chen, X. N. Hu, J. S. Yu and L. M. Wu, Chem. -Asian J., 2017, 12, 453-458.

65 H. Lin, L. Chen, J. S. Yu, H. Chen and L. M. Wu, Chem. Mater., 2017, 29, 499-503.

66 S. K. Kurtz and T. T. Perry, J. Appl. Phys., 1968, 39, 37983813.

67 Crystal Clear, version 1.3.5, Rigaku Corp., The Woodlands, TX, 1999.

68 G. M. Sheldrick, SHELXTL, version 5.1, Bruker-AXS, Madison, WI, 1998.
69 (a) G. Kresse and J. Furthmuller, Phys. Rev. B: Condens. Matter, 1996, 54, 11169-11186; (b) J. P. Perdew and Y. Wang, Phys. Rev. B: Condens. Matter, 1992, 45, 1324413249; (c) G. Kresse and D. Joubert, Phys. Rev. B: Condens. Matter, 1999, 59, 1758-1775; (d) P. E. Blöchl, Phys. Rev. B: Condens. Matter, 1994, 50, 17953-17979; (e) P. E. Blöchl, O. Jepsen and O. K. Andersen, Phys. Rev. B: Condens. Matter, 1994, 49, 16223-16234.

70 R. Graucrespo, S. Hamad, C. R. A. Catlow and N. H. D. Leeuw, J. Phys.: Condens. Matter, 2007, 19, 219.

71 (a) C. Aversa and J. E. Sipe, Phys. Rev. B: Condens. Matter, 1995, 52, 14636-14645; (b) S. N. Rashkeev, W. R. L. Lambrecht and B. Segall, Phys. Rev. B: Condens. Matter, 1998, 57, 3905-3919.

72 J. P. Perdew, K. Burke and M. Ernzerhof, Phys. Rev. Lett., 1996, 77, 3865-3868. 